\title{
Índices de qualidade da paisagem no campo petrolifero de Carmópolis, Sergipe
}

O campo petrolífero de Carmópolis, um dos maiores produtores de petróleo on shore do país, é importante economicamente para o Estado de Sergipe; contudo causa impactos ambientais significativos. A fim de subsidiar o processo de licenciamento, esta pesquisa objetivou analisar a qualidade da paisagem nos municípios de Carmópolis e Japaratuba, por meio de índices. Constatou-se que: os índices de qualidade da paisagem do município de Carmópolis e Japaratuba são, respectivamente, 0,54 e 0,55, classificado como regular; a pecuária é matriz das paisagens de ambos os municípios; os poços, as estradas e os dutos de gás e petróleo fragmentam as paisagem, comprometendo as resiliências dos ecossistemas naturais. Assim, as hipóteses de que as paisagens dos municípios de Carmópolis e Japaratuba estão sendo degradadas pela atividade petrolífera e de que os impactos ambientais não estão sendo mitigados adequadamente foram confirmadas. Para revertem o processo de degradação, torna-se mister a implantação de ações de manejo prioritárias para cessar, minimizar e compensar os impactos ambientais; assegurar a proteção dos ecossistemas naturais e a qualidade de vida da população. Dentro desse contexto, a fiscalização, a recuperação ambiental, a implantação de corredores ecológicos por meio do reflorestamento com espécies nativas são ferramentas importantes para planejamento ambiental da mineração no Campo Petrolífero de Carmópolis.

Palavras-chave: Mineração Terrestre; Geoprocessamento; Ecologia da Paisagem.

\section{Quality index of the landscape in the Carmópolis field, Sergipe}

\begin{abstract}
The Carmópolis Field, one of the largest onshore oil producers in the country, is economically important for the State of Sergipe; yet has significant environmental impacts. In order to subsidize the licensing process, this research aimed to analyze the quality of the landscape in the municipalities of Carmópolis and Japaratuba, through indexes. It was verified that: the quality indices of the landscape of the municipality of Carmópolis and Japaratuna are, respectively, 0.54 and 0.55 , classified as regular; the wells, the roads and the gas and oil pipelines fragments the landscape of the municipality, compromising the resiliency of natural ecosystems. hus, the assumptions that the landscapes of the municipalities of Carmópolis and Japaratuba are being degraded by oil activity and that the environmental impacts are not being adequately mitigated have been confirmed. In order to reverse the degradation process, it is necessary to implement priority management actions to cease, minimize and compensate for environmental impacts; ensure the protection of natural ecosystems and the quality of life of the population. Within this context, monitoring, environmental recovery, and the implementation of ecological corridors through reforestation with native species are important tools for environmental planning of mining in the Carmópolis Oil Field.
\end{abstract}

Keywords: Landscape AQality; Geoprocessing; Landscape ecology.

Topic: Desenvolvimento, Sustentabilidade e Meio Ambiente

Reviewed anonymously in the process of blind peer.
Received: 12/04/2019

Approved: 27/05/2019

Ivana Silva Sobral (iD)

Universidade Federal de Sergipe, Brasil

http://lattes.cnpq.br/2221246547084492

http://orcid.org/0000-0001-7435-2496

ivana.sobral@hotmail.com

Gicélia Mendes Silva

Universidade Federal de Sergipe, Brasil

http://lattes.cnpq.br/2858199391215049

ivana.sobral@hotmail.com

Daniela Monique Guimarães Menezes

Universidade Federal de Sergipe, Brasil

http://lattes.cnpq.br/0106110690747598

ivana.sobral@hotmail.com

\section{Referencing this:}

SOBRAL, I. S.; SILVA, G. M.; MENEZES, D. M. G.. Índices de qualidade da paisagem no campo petrolífero de Carmópolis, Sergipe. Revista Ibero Americana de Ciências Ambientais, v.10, n.3, p.219-227, 2019. DOI: http://doi.org/10.6008/CBPC2179-6858.2019.003.0019 


\section{INTRODUÇÃO}

A Política Nacional de Meio Ambiente, instituída pela Lei n 6.938 de 31 de agosto 1981, considerada marco da gestão ambiental no Brasil, ao enquadrar a mineração petrolífera como atividade altamente poluidora, sujeita-a ao processo de licenciamento ambiental. De acordo com a referida política, o licenciamento ambiental para esta atividade deve acontecer por meio de 04 fases: Licença Prévia para Perfuração, Licença Prévia para Produção, Licença de Implantação e Licença Operação.

Apesar de o licenciamento ambiental ter caráter preventivo, por trata-se de processo prévio de controle ambiental para o exercício legal de atividades modificadoras do meio ambiente; no Estado de Sergipe, a exploração petrolífera vem acontecendo de maneira desordenada, causando uma série de impactos negativos que comprometem a qualidade da paisagem dos municípios que o circunscreve.

Diante dos impactos negativos da atividade petrolífera, faz-se necessário o estudo espacial das implicações ambientais da produção de petróleo no Campo de Carmópolis, um dos maiores do país, a fim de traçar estratégias de planejamento ambiental visando proteger as áreas naturais remanescentes; assegurar a qualidade de vida das populações e tornar a relação homem \natureza mais harmônica. Como instrumentos de planejamento ambiental, o estudo da qualidade da paisagem é fundamental para subsidiar a proposição de medidas mitigadoras e compensatórias.

Os municípios de Carmópolis e Japaratuba, localizados no campo petrolífero de Carmópolis, são um dos maiores produtores de petróleo on shore no país. Em função da vulnerabilidade ambiental de seus ecossistemas, faz-se necessário o estudo da qualidade da paisagem a fim de subsidiar o processo de licenciamento e planejamento ambiental.

Isto posto, esta pesquisa objetivou analisar a qualidade da paisagem nos municípios de Carmópolis e Japaratuba, localizados do Campo Petrolífero de Carmópolis, visando subsidiar o processo de licenciamento ambiental. No intuito de alcançar o objetivo principal, foi proposto o seguintes objetivos específicos: mesurar os índices de qualidade da paisagem; analisar s implicações espaciais da produção de petróleo onshore e propor medidas mitigadoras e compensatórias dos impactos ambientais.

\section{REVISÃO TEÓRICA}

O planejamento sob a ótica ambiental visa integrar informações, diagnosticar o ambiente, prever ações e normatizar seu uso através de uma linha ética de desenvolvimento. Compartilhando deste enfoque, estão aqueles que se preocupam com a conservação das bases lógicas sociais e econômicas que regem uma determinada área de interesse. Assim, os princípios do planejamento ambiental propõe elaborar uma análise em que a tríade meio, sociedade e natureza passa a ser entendida como uma unidade coesa.

Em 1930, o alemão Carl Troll, lança as bases da Ecologia da Paisagem, método que mais tarde ele mesmo designou de Geoecologia e o definiu como "o estudo das relações físico-biológicas que governam as diferentes unidades espaciais de uma região" (FORMAN et al., 1986). Este método representou um progresso sobre os estudos fragmentados, por agrupar todos os elementos da paisagem sem se esquecer do ser 
humano (NUCCl, 2004).

Seguindo os preceitos de Troll, Ernest Neef nos anos de 1960, adotou em seus estudos na exRepública Democrática alemã o termo ecologia de paisagem. De acordo com Neef (1967, citado por TRICARD, 1977): "cada paisagem comporta alguns elementos comuns, que são os princípios da homogeneidade, que constituem em apenas uma parte de suas características".

As áreas homogêneas chamadas de 'unidades da paisagem' foram definidas por Bertrand, levandose em consideração não apenas um ou outro elemento, mas o resultado global da combinação dos elementos paisagísticos, o que se reflete, segundo a dinâmica do conjunto, na sua fisionomia (SILVEIRA, 2007). Ou seja, Bertrand compreende a paisagem como uma determinada porção do espaço, resultante da combinação dinâmica, de elementos físicos, biológicos e antrópicos que interagem entre si e que estão em perpétua evolução (CRUZ, 1972).

Bertrand (1968) sugeriu um sistema taxonômico que permite classificar as paisagens em seis níveis temporoespaciais (zona, domínio, região, geossistema, geofácies e geótopo), sendo cada nível considerado uma 'unidade de paisagem determinada em função da escala. Em meio a estas unidades da paisagem, Bertrand (citado por NUCCI, 2004) destaca o geossistema, que foi definido por ele como o fruto das relações entre o potencial ecológico, a exploração biológica e a ação antrópica.

A Teoria Geossistêmica foi conceituada, no início dos anos 1960 pelo russo Sotchova, como o estudo das paisagens geográficas complexas e aprofundada por Bertrand em 1968. Este corrobora com as premissas de Sotchova, ao definir geossistema como um sistema natural de nível local, regional ou global que resulta da combinação de fatores geomorfológicos, climáticos e hidrológicos e se define por certo tipo de exploração biológica do espaço. Na maioria das vezes, o geossistema é formado de paisagens diferentes, que são ligadas umas às outras por meio de uma série dinâmica que tende para um mesmo clímax.

A partir do advento da abordagem sistêmica, a paisagem é apresentada como categoria de análise concreta, passível de representação cartográfica (TRICART, 1982). Com a inclusão da Teoria Geral dos Sistemas no arcabouço teórico-metodológico da Geografia Física, a paisagem começa a ser estudada segundo sua dinâmica, apontando sempre para sua funcionalidade e com interesse na organização derivada das interações e interdependências entre os atributos constituintes (PEREIRA NETTO, 2000).

Por considerarem o estudo integrado da paisagem, indicando caminhos que são mais adequados para responderem as necessidades e problemas concretos gerados pela sociedade na atualidade, a ecologia de paisagem e o geossistema configuram-se como modelos teóricos que respondem às alterações espaciais causadas pela ação antrópica e que refletem na organização espacial e na diferenciação das paisagens (SILVEIRA, 2007).

A noção básica de paisagem é a espacialidade, a heterogeneidade do espaço onde o homem habita (TROLL). A heterogeneidade que constitui uma paisagem engloba aspectos geomorfológicos e de recobrimento tanto naturais quanto culturais (METZGER, 1991). Para expressar a heterogeneidade do espaço, a ecologia da paisagem trabalha com três características da paisagem: a 'estrutura' composta pelas relações entre os distintos ecossistemas ou elementos presentes em relação ao tamanho, forma, número, 
tipo e configuração; o 'funcionamento', que se traduz nos fluxos de energia, matéria e espécies dentro da paisagem; e as 'alterações' que são as modificações observadas na estrutura e fluxos do mosaico ecológico (FORMAN et al., 1986).

A estrutura da paisagem é composta por matriz, elemento que tem domínio na paisagem; manchas, fragmentos não lineares de aparente homogeneidade que interrompe a matriz; e corredores, elementos lineares de aparente homogeneidade e distinguíveis na matriz (Figura 3). Estes elementos são a base cognitiva que permite a comparação entre paisagens distintas e torna a linguagem espacial quando se combinam para formar a variedade de lands mosaics na terra (CASIMIRO, 2007).

A definição de que o elemento da paisagem é matriz, mancha ou corredor está relacionado à escala. A escala é utilizada para referir a diferentes noções: a escala espacial inclui a extensão no espaço; a escala temporal inclui um aspecto de duração e resolução; a escala geográfica indica a representação de um objeto no solo; e a escala de percepção dos ecossistemas que se refere à escala espacial e temporal na qual o ecossistema em estudo interage com a paisagem. No entanto, qualquer porção da Terra é homogênea numa escala mais abrangente e heterogênea quando vista em uma escala mais detalhada (METZGER, 1991).

Atualmente, além dos mapas temáticos em diversas escalas, outras fontes de informação cartográfica são preconizadas para a avaliação da paisagem, entre elas as imagens obtidas por sensores a bordo de satélites, as fotografias aéreas e os sistemas de informações geográficas (SIG) (ROCHA, 1995). A valoração da paisagem é considerada um recurso que permite avaliar a qualidade de uma região com rapidez e eficácia (LANDOVSKY et al., 2006). A união da ecologia da paisagem com os sistemas de informações geográficos permitem avaliar mosaicos antropizados na proporção em que o homem está modificando o seu ambiente (METZGER, 1991).

Assim, o objeto de estudo da ecologia da paisagem torna-se diferenciado e mais apropriado porque observa um conjunto de unidades naturais, alteradas ou substituídas por ação humana, que compõe um intricado, heterogêneo e interativo mosaico. Os planejadores interpretam este mosaico, traduzem a heterogeneidade e revelam as relações ou processos ativos entre as unidades. O resultado deste trabalho é a compreensão dos efeitos humanos sobre o meio ambiente e a elaboração de estratégias de manejo orientadas pelos elementos descritores da paisagem (SANTOS, 2004).

O conceito de paisagem proposto evidencia que a paisagem não é somente um amplo espaço geográfico ou um novo nível hierárquico do estudo da ecologia, justo acima de ecossistemas, pois a escala e o nível biológico da análise dependem do observador e do objeto de estudo. A ecologia da paisagem vem promovendo uma mudança de paradigma nos estudos sobre fragmentação e conservação de ecossistemas, pois permite a integração da heterogeneidade espacial e do conceito de escala na análise ecológica (METGER, 1991), tornando esse trabalho ainda mais aplicado para o tratamento de problemas ambientais.

\section{METODOLOGIA}

Os municípios de Carmópolis e Japaratuba, localizados na região do Baixo Cotinguiba, situados na Bacia Sedimentar Sergipe-Alagoas, possuem parte de seus limites administrativos sobre o campo petrolífero 
de Carmópolis, o maior campo de petróleo on shore do Brasil. Para análise da qualidade da paisagem desses municípios, os usos do solo desses municípios foram mapeados e analisados a partir da fotointerpretação de imagens de satélite RapidEye (MMA, 2012), fotografias aéreas (SEPLAN, 2012) e dados coletados em campo. Em seguida, elaborou-se mapas de qualidade da paisagem no software livre Quantum GIS que possui funções de processamento de bancos de dados espaciais.

No intuito de mesurar os índices de qualidade da paisagem e analisar as implicações espaciais da produção de petróleo onshore, os componentes das paisagens foram valorados quantitativamente e qualitativamente, conforme o sistema proposto por esta pesquisa, a partir da metodologia adaptada de Landovsky et al. (2006) (Tabela 1).

Tabela 1: Índices propostos por essa pesquisa para valoração da paisagem em municípios com exploração de petróleo onshore

\begin{tabular}{|l|l|}
\hline Componente da Paisagem & Índice dos componentes \\
\hline Vegetação nativa & \multirow{2}{*}{1,0} \\
\hline APP com vegetação nativa & \\
\hline Rio, riacho & \multirow{2}{*}{0,75} \\
\hline Açude, barragem & \multirow{2}{*}{0,50} \\
\hline Área alagada & \multirow{2}{*}{0,25} \\
\hline Coqueiral & \\
\hline Cultura agrícola & \multirow{2}{*}{0} \\
\hline Pastagem & \\
\hline APP sem vegetação nativa & \\
\hline Sede municipal & \\
\hline Área construída & \\
\hline Estrada &
\end{tabular}

A metodologia utilizada para avaliar a qualidade ambiental dos componentes das paisagens foi proposta conforme justificativa proposta por esta pesquisa, conforme descrito a seguir: i. Qualidade Muito Alta: A qualidade dos componentes das paisagens 'Vegetação Nativa' em área de preservação permanente e 'Corpo d'água' foram classificados como MUITO ALTA, em virtude desta pesquisa considerar estes componentes os elementos principais para a sustentabilidade das paisagens dos municípios produtores de petróleo onshore; ii. Qualidade Alta: Os componentes das paisagens 'Vegetação Nativa' e 'Cultura de subsistência' foram classificados como de Qualidade Alta, uma vez que são importantes para a sustentabilidade das paisagens; iii. Qualidade Média: As unidades de paisagens 'Monocultura' e 'Pastagem' foram classificadas como de MÉDIA qualidade, uma vez que apesar se constituírem como atividades fundamentais para a econômica local, são prejudiciais para a sustentabilidade ambiental; iv. Qualidade Baixa: As unidades de paisagem 'Núcleo Urbano' e 'Estradas' foram classificadas como de qualidade BAIXA, porque impermeabilizam o solo e fragmentam os ecossistemas naturais; v. Qualidade Muito Baixa: As unidades de paisagens 'Áreas Degradadas' e 'Mineração' foram classificadas como de qualidade MUITO BAIXA porque fragmentam as paisagens e causam danos irreversíveis ao meio ambiente. Os índices de qualidade das paisagens foram calculados por meio da fórmula proposta por Sobral (2012).

$\underline{I Q P A}=(\% \mathrm{Ac} 1 \times \mathrm{Vc} 1)+(\% \mathrm{Ac2} \times \mathrm{Vc})+(\% \mathrm{Ac3} \times \mathrm{Vc3})+(\% \mathrm{Ac4} \times \mathrm{Vc4})+(\% \mathrm{Ac4} \times \mathrm{Vc4})$

Legenda: QPA = Qualidade da Paisagem 
Após a mensuração do índice, a qualidade das paisagens dos municípios de Carmópolis e Japaratuba foi classificada com base nos critérios descritos na Tabela 2.

Tabela 2: Classificação dos índices de qualidade das paisagens dos municípios.

\begin{tabular}{|l|l|}
\hline ÍNDICE DA QUALIDADE DA PAISAGEM (0 - $\mathbf{1})$ & QUALIDADE DA PAISAGEM DO PA \\
\hline $0,80<$ Índice $\leq 1,0$ & IDEAL \\
\hline $0,60<$ Índice $\leq 0,80$ & BOM \\
\hline $0,40<$ Índice $\leq 0,60$ & REGULAR \\
\hline $0,20<$ Índice $\leq 0,40$ & RUIM \\
\hline $0<$ Índice $\leq 0,20$ & PÉSSIMO \\
\hline
\end{tabular}

Fonte: Adaptada de Martins et al. (2008).

\section{RESULTADOS E DISCUSSÃO}

O estudo da paisagem é considerado como importante recurso para as questões ambientais, uma vez que revela a forma de como o espaço geográfico se encontra em função de sua utilização (LANDOVSKY, 2009). A qualidade da paisagem representa o nível de excelência das suas características visuais, cuja diversidade torna difícil a sua avaliação em termos absolutos; sendo, portanto, necessária à adoção de métodos baseados em juízos de valor (HARDT, 2004). No intuito de sintetizar a influência da mineração petrolífera on shore. hore nos componentes espaciais dos municípios de Carmópolis e Japaratuba, foi proposto a avaliação da qualidade da paisagem por meio de índices.

Durante a análise da qualidade da paisagem foi possível identificar alterações significativas causadas pela atividade petrolífera. Observou-se ainda que, o componente 'Pastagem' é a matriz da paisagem por ser o elemento espacial dominante desses municípios, estando presente em $48,29 \%$ da área municipal de Carmópolis e 45,98\% de Japaratuba (Tabela 3). A matriz é interrompida por manchas, como 'Coqueiral', 'Vegetação Nativa'; 'Cultura Agrícola'; 'Sede Municipal'; 'Área Construída'; 'Mineração de petróleo e gás'; 'Área alagada'; 'Solo exposto ou degradado' e 'Recursos Hídricos'. Os corredores 'APPs' e 'Rios e riachos' interligam as manchas positivamente; já o corretor 'Estrada' interliga as manchas causando impactos negativos, uma vez que fragmentam as paisagens e consequentemente os ecossistemas, impedindo assim o fluxo gênicos entre os fragmentos florestais.

Em ambos os municípios, a matriz 'pastagem' recobre o solo tanto nas áreas municipais produtoras de petróleo, quanto nas áreas não produtoras. A pecuária é extensiva e os animais são criados soltos, muitas vezes alimentando-se nos arredores dos poços de exploração, em áreas contaminadas por derramamento de óleo e vazamento de gás, o que põe em dúvida a qualidade da carne, do leite e derivados produzidos no município e comercializados em todo Estado de Sergipe. De acordo com Netto et al. (2000), os hidrocarbonetos policíclicos aromáticos (HPAs), componentes do petróleo, são poluentes orgânicos de importância ambiental e interesse toxicológico, pois muitos apresentam propriedades pré-carcinogênicas e/ou mutagênicas para homens e animais.

As manchas de mineração que interrompem a matriz apresentam qualidade muito baixa por impactarem negativamente a paisagem por meio de poços de petróleo, estradas de acesso estruturas de 
apoio à exploração petrolífera, tais como estações coletoras de petróleo e instalação dos dutos e tráfego de veículos pesados, causando supressão de vegetação; afugentamento da fauna silvestre; produção de ruído; vazamentos de gás e petróleo e consequentemente contaminação da água, ar e solo.

Tabela 3: Classes de uso e ocupação do solo dos municípios de Carmópolis e Japaratuba e suas respectivas áreas em percentagem.

\begin{tabular}{|l|l|l|}
\hline Classes de ocupação do solo & Áreas Carmópolis (\%) & Áreas Japaratuba (\%) \\
\hline APP & $0,15 \%$ & $1,60 \%$ \\
\hline Coqueirais & $12,98 \%$ & $2,02 \%$ \\
\hline Recursos hidricos & $0,15 \%$, & $0,17 \%$ \\
\hline Sede municipal & $3,35 \%$ & $0,20 \%$ \\
\hline Estradas & $1,30 \%$ & $1,96 \%$ \\
\hline Áreas construídas & $2,86 \%$, & $0,19 \%$ \\
\hline Mineração de petróleo e gás & $2,31 \%$ & $0,76 \%$ \\
\hline Vegetação Nativa & $10,49 \%$ & $17,45 \%$ \\
\hline Cultivos & $7,62 \%$ & $18,38 \%$ \\
\hline Pastagens & $48,29 \%$ & $45,98 \%$ \\
\hline Solos expostos ou degradados & $0,215 \%$ & $11,29 \%$ \\
\hline
\end{tabular}

O componente da paisagem 'vegetação nativa' ocupa 10,49\% e 17,45\%, em Carmópolis e Japaratuba, respectivamente. Assim, observa-se que o município de Japaratuba apresenta pequeno déficit de vegetação nativa, no entanto, o município de Carmópolis, encontra-se com déficit de 3.446 .968 hectares, aproximadamente. Em ambos os municípios, os ecossistemas estão fragmentados, em virtude da supressão de vegetação nativa para a implantação de poços, estradas e tubulações de petróleo e gás.

Apesar de as Áreas de Preservação Permanente (APPs) serem espaços territoriais protegidos de acordo com o disposto no inciso III, § 1으, do art. 225 da Constituição Federal, nas áreas produtoras de petróleo, a maior parte encontra-se desmatada, estando ocupadas por poços, estradas e construções que servem à mineração.

A Legislação Florestal, por meio da Lei Federal n 12.651 (BRASIL, 2012), destaca a importância das APP's para a preservação dos recursos hídricos, da paisagem; da estabilidade geológica, da biodiversidade, do fluxo gênico de fauna e flora. Além disto, assegura o bem-estar das populações humanas. Ou seja, as APP's, se conservadas, são fundamentais para a qualidade das paisagens.

As 'estradas', do ponto de vista econômico e social, constituem-se em corredores importantes para o fluxo de pessoas, produtos, insumos e manutenção dos poços de petróleo e gás; no entanto, no aspecto ambiental, é responsável por fragmentar ecossistemas naturais fundamentais para a o equilíbrio ambiental. Os recursos hídricos são manchas essenciais para a sobrevivência dos seres vivos e para a sustentabilidade das paisagens, por formarem corredores ecológicos necessários ao equilíbrio ambiental. Apesar disso, observou-se algumas áreas, próximas aos mananciais, contaminadas por petróleo.

A partir dos mapas de uso e ocupação do solo, elaborou-se mapas qualidade da paisagem dos municípios de Carmópolis e Japaratuba, onde contatou-se que, respectivamente, 11,51\% e 19,05\% das áreas municipais apresentam qualidade muito alta; $11,26 \%$ e 2,19\%, alta; $55,90 \%$ e $64,36 \%$, média; $13,71 \%$, baixa e 3,93 \% e 0,39\%, muito baixa. O que resulta em índice de qualidade da paisagem regulares para ambos os municípios, já tem o índice de Carmópolis foi 0,54 e de Japaratuba 0,55 (Tabelas 4 e 5). 
Tabela 4: Índice da qualidade da paisagem do município de Carmópolis, Sergipe.

\begin{tabular}{|l|l|l|}
\hline Qualidade das Classes das Paisagens & Percentuais das áreas das classes & Índice de qualidade da paisagem \\
\hline Muito alta & $11,51 \%$ & $11,51 \times 1,00=11,51$ \\
\hline Alta & $15,02 \%$ & $15,02 \times 0,75=11,26$ \\
\hline \multicolumn{1}{|c|}{ Média } & $55,90 \%$ & $55,90 \times 0,50=27,95$ \\
\hline Baixa & $13,71 \%$ & $13,71 \times 0,25=3,43$ \\
\hline Muita baixa & $3,83 \%$ & $3,83 \times 0,00=0,00$ \\
\hline Índice de qualidade da paisagem do município de Carmópolis & $54,14 / 100$ \\
\cline { 2 - 3 } & 0,54 (Regular) \\
\hline
\end{tabular}

Tabela 5: Índice da qualidade da paisagem do município de Japaratuba, Sergipe.

\begin{tabular}{|l|l|l|}
\hline Qualidade das Classes das Paisagens & Percentuais das áreas das classes & Índice de qualidade da paisagem \\
\hline Muito alta & $19,05 \%$ & $19,05 \times 1,00=19,05$ \\
\hline Alta Média & $2,19 \%$ & $2,19 \times 0,75=1,64$ \\
\hline \multicolumn{1}{|c|}{ Baixa } & $64,36 \%$ & $64,36 \times 0,50=34,61$ \\
\hline Muita baixa & $0,39 \%$ & $0,39 \times 0,25=0,10$ \\
\hline \multicolumn{2}{|l|}{ Índice de qualidade da paisagem do município de Japaratuba } & $14,01 \times 0,00=0,00$ \\
& $14,01 \%$ & $\mathbf{5 5 , 3 0 / 1 0 0}$ \\
\cline { 2 - 3 } & $\mathbf{0 , 5 5}$ (Regular) \\
\hline
\end{tabular}

Após a definição do IQPA para os municípios de Carmópolis e Japaratuba, observou-se que os valores calculados são muito próximos, apesar de apresentarem algumas classe do uso e ocupação do solo, distintas. Sendo assim, inferiu-se que o componente que mais influencia negativamente a paisagem é a mineração de petróleo e gás.

Assim sendo, as hipóteses de que as paisagens dos municípios de Carmópolis e Japaratuba estão sendo degradadas pela atividade petrolífera e de que os impactos ambientais não estão sendo mitigados adequadamente foram confirmadas. Para revertem o processo de degradação, torna-se mister a implantação de ações de manejo prioritárias para cessar, minimizar e compensar os impactos ambientais advindos da produção de petróleo onshore; assegurar a proteção dos ecossistemas naturais e a qualidade de vida da população. Dentro desse contexto, a fiscalização do processo de licenciamento ambiental; a recuperação da qualidade da paisagem das áreas mineradas; a implantação de corredores ecológicos por meio do reflorestamento com espécies nativas são ferramentas importantes para planejamento ambiental.

\section{CONCLUSÕES}

Diante das implicações ambientais constatadas no Campo Petrolífero de Carmópolis, por meio dos índices de qualidade da paisagem, faz-se necessário que os princípios do poluidor pagador e da cooperação, consagrados pela Constituição Federal Brasileira sejam internalizados no processo de planejamento ambiental.

O princípio do poluidor-pagador, por seu caráter econômico, deve ser utilizado para exigir da Petrobrás que internalize seus impactos negativos, arcando com as despesas indispensáveis à diminuição, eliminação ou neutralização dos prejuízos socioambientais provocados. Já o princípio da cooperação, por sua natureza social, considera que a preservação ambiental é um direto difuso e coletivo, requerendo assim, a participação popular no processo decisório, ao lado do Poder Público e da Petrobrás, acerca dos impactos e da recuperação de áreas degradadas.

Além da internalização dos princípios do poluidor pagador e da cooperação pela atividade minerária 
nos municípios de Carmópolis e Japaratuba, é de suma importância que o órgão ambiental licenciador, fiscalize regularmente para a verificação o cumprimento das condicionantes das licenças ambientais. E, quando constatado descumprimento, as sanções previstas na legislação vigente sejam aplicadas.

\section{REFERÊNCIAS}

BRASIL. Lei n. 12.651: 2012. Dispõe sobre a proteção da vegetação nativa; e dá outras providências. Brasília: DOU, 2012.

FORMAN, R. T. T.; GODROM, M.. Landscape Ecology. New York: John Wiley \& Sons, 1986.

HARDT, L. P. A.. Ecologia da paisagem: fundamentos à gestão do espaço urbano. OLAM: Ciência \& Tecnologia, Rio Claro, v.4, p.597-612, 2004.

LANDOVSKY, G. S.; ARAKI, H.; BATISTA, D. B.. Análise da qualidade visual da paisagem da região de Tibagi, PR, aplicando o sensoriamento remoto. Revista Brasileira de Engenharia Agrícola e Ambiental, Campina Grande, v.10, p.188-195, 2006.

LANDOVSKY, G. S.. Utilização de imagens CBERS para a avaliação da qualidade visual da paisagem. In: SIMPÓSIO BRASILEIRO DE SENSORIAMENTO REMOTO, 14. Anais. Natal, 2009.

MARTINS, M. F.; CÂNDIDO, G. A.. Índice de Desenvolvimento Sustentável para Municípios (IDSM):
Metodologia para análise e cálculo do IDSM e classificação dos níveis de sustentabilidade: uma aplicação no Estado da Paraíba. João Pessoa: SEBRAE, 2008.

MMA. Ministério do Meio Ambiente. Imagens de satélites RapidEye. Brasília: MMA, 2012.

PEREIRA NETTO, A. D.; MOREIRA, J. C.; ARBILLA, G. FERREIRA L. F. V.; OLIVEIRA S. A.; BAREK, J.. Avaliação da contaminação humana por hidrocarbonetos policíclicos aromáticos (HPAs) e seus derivados nitratos (NHPAS): Uma revisão metodológica. Química Nova, São Paulo, v.23, n.6, p.265- 273, 2000. DOI: http://dx.doi.org/10.1590/S010040422000000600010

SANTOS, R. F.. Planejamento Ambiental: teoria e prática. São Paulo: Oficina de textos, 2004.

SOBRAL, I. S.. Instrumentos de gestão ambiental como subsídio para o desenvolvimento sustentável dos projetos de assentamentos de reforma agrária de Sergipe. Tese (Doutorado) - Universidade Federal de Sergipe, São Cristóvão, 2012.

A CBPC - Companhia Brasileira de Produção Científica (CNPJ: 11.221.422/0001-03) detém os direitos materiais desta publicação. Os direitos referem-se à publicação do trabalho em qualquer parte do mundo, incluindo os direitos às renovações, expansões e disseminações da contribuição, bem como outros direitos subsidiários. Todos os trabalhos publicados eletronicamente poderão posteriormente ser publicados em coletâneas impressas sob coordenação da Sustenere Publishing, da Companhia Brasileira de Produção Científica e seus parceiros autorizados. Os (as) autores (as) preservam os direitos autorais, mas não têm permissão para a publicação da contribuição em outro meio, impresso ou digital, em português ou em tradução. 